\title{
Efficacy and safety of hydroxychloroquine when added to stable insulin therapy in combination with metformin and glimepiride in patients with type 2 diabetes compare to sitagliptin
}

\author{
Vijay Kumar, M. P. Singh, Amrendra Prasad Singh*, Mani Shankar Pandey, \\ Suraj Kumar, Sumit Kumar
}

\begin{abstract}
Department of Medicine, Medicine, Patna Medical College and Hospital, Patna, Bihar, India
\end{abstract}

Received: 20 July 2018 Accepted: 29 August 2018

*Correspondence to:

Dr. Amrendra Prasad Singh, Email: amrendraprasadsingh@ rediffmail.com

Copyright: (C) the author(s), publisher and licensee Medip Academy. This is an openaccess article distributed under the terms of the Creative Commons Attribution NonCommercial License, which permits unrestricted noncommercial use, distribution, and reproduction in any medium, provided the original work is properly cited.

\begin{abstract}
Background: The trial was done to evaluate the efficacy and tolerability of hydroxychloroquine when added to stable insulin therapy in combination with metformin and glimepiride in patients with type 2 diabetes (T2DM) compare to sitagliptin.

Methods: After two weeks run in period, eligible patients inadequately controlled on long acting, intermediate acting or premixed insulin (HbA1c $\geq 7.5 \%$ and $\leq 10 \%$ ), in combination with metformin and glimepiride were randomised 1:1 to the addition of once daily hydroxychloroquine $400 \mathrm{mg}$ or sitagliptin $100 \mathrm{mg}$ over 24weeks study period. The primary endpoint was HbAlc change from baseline at week 24. Home based glucometer was used to determine finger stick glucose value to detect hypo or hyperglycemia periodically.

Results: At 24 weeks, the addition of hydroxychloroquine significantly (p $<0.001$ ) reduced HbA1c by $1.3 \%$ compared with Sitagliptin which was $0.9 \%$. A greater proportion of patients achieved an $\mathrm{HbA} 1 \mathrm{c}$ level $<7 \%$ while randomised to Hydroxychloroquine as compared with sitagliptin (31 vs. $18 \%$ respectively; $p$ $<0.001)$. The addition of hydroxychloroquine significantly $(\mathrm{p}<0.001)$ reduced fasting plasma glucose by $31.0 \mathrm{mg} / \mathrm{dl}$ (vs $23.2 \mathrm{mg} / \mathrm{dl}$ with sitagliptin) and post prandial plasma glucose by $52.1 \mathrm{mg} / \mathrm{dl}$ (vs $41 \mathrm{mg} / \mathrm{dl}$ with sitagliptin) relative to sitagliptin. The difference in mean value of total daily insulin dose showed a highly significant decrease $(\mathrm{P}<0.0001)$ from baseline to end of the treatment with hydroxychloroquine i.e. from $41 \pm 10.2$ to $31.87 \pm 16.49$ IU as compare to sitagliptin i.e. from $41 \pm 10.6$ to $37.91 \pm 11.71 \mathrm{IU}$. And also highly significant (P $<0.0001$ ) decrease in mean weight was observed at the end of trial with hydroxychloroquine.

Conclusions: Hydroxychloroquine decreases HbA1c in patients whose type 2 diabetes is poorly controlled with stable-dose insulin therapy with metformin and glimepiride.
\end{abstract}

Keywords: Hydroxychloroquine, HbA1c, Glimepiride, Insulin, Metformin, T2DM, Sitagliptin

\section{INTRODUCTION}

Type 2 diabetes is characterized by an impaired sensitivity of target tissues to insulin and impaired insulin secretion by pancreatic $\beta$ cells, which leads to hyperglycemia and, over time, to micro vascular and macro vascular complications. ${ }^{1,2}$ Results of the U.K. Prospective Diabetes Study (UKPDS) have shown that improvement of glycemic control reduces these complications and that progressive $\beta$ cell failure usually leads to the need for combination therapy to maintain glycemic control. ${ }^{3}$ The UKPDS demonstrated that even insulin treated patients were unable to sustain adequate glycemic control. Due to the progressive nature of type 2 diabetes, many patients do not achieve or maintain glycaemic control on oral anti hyperglycaemic agents or insulin monotherapy. ${ }^{4}$ Insulin therapy in combination with oral anti hyperglycaemic 
agents is effective, but over time many patients still fail to reach currently recommended $\mathrm{HbA} 1 \mathrm{c}$ treatment goals. ${ }^{5,6}$

Sitagliptin is a potent and selective inhibitor of dipeptidyl peptidase-IV (DPP-4) that improves glycaemic control in patients with type 2 diabetes, primarily by enhancing pancreatic islet function. Thus, sitagliptin has been shown both to increase beta cell responsiveness to glucose and to suppress the inappropriate glucagon secretion seen in patients with type 2 diabetes. Sitagliptin is effective as monotherapy, as initial combination therapy with metformin, and as add-on therapy to oral anti hyperglycaemic agents. ${ }^{7}$

Hydroxychloroquine is a potent antidiabetic drug which blocks the insulin degrading enzyme (IDE) by altering cell $\mathrm{pH}$ and therefore increase the insulin half-life. Drug Controller General of India (DCGI) has already approved Hydroxychloroquine $400 \mathrm{mg}$ to be used as ad on treatment in uncontrolled T2DM patients who are on sulphonyl urea and metformin. Hydroxychloroquine is effective as an add on to sulfonylurea and metformin and evaluated against newer agents like pioglitazone, teneligliptin, vildagliptin and sitagliptin. ${ }^{8-11}$ All the trials till now conducted with hydroxychloroquine $400 \mathrm{mg}$ has confirmed its superior potency of HbA1c reduction in uncontrolled T2DM patients. Even addition of hydroxychloroquine 400mg can reduce the daily insulin dosage almost by $28 \%$, which has demonstrated in recent clinical trial conducted in India by Baidya A et al. ${ }^{12}$

The complementary effects of hydroxychloroquine and insulin on fasting and postprandial glucose control provide a rational basis for these agents to be used together. Even DPP4i like sitagliptin has already demonstrated its potent efficacy and safety when added to insulin therapy in patients with type 2 diabetes. ${ }^{13}$ Thus, the present study compare the efficacy and safety of hydroxychloroquine vs. sitagliptin when added to insulin along with other oral therapy (metformin + glimepiride) in patients with uncontrolled type 2 diabetes.

\section{METHODS}

The protocol was reviewed and approved by the appropriate committees and authorities and performed in accordance with the Declaration of Helsinki. Patient's provided written informed consent to participate.

This multicentre, randomised, open label, parallel-group observational study was performed at multiple private clinical sites and Medical College OPD across Patna city, Bihar, India. This study will screen type 2 diabetes mellitus patients aged between $\geq 18$ years and $\leq 65$ years with body weight $\geq 60 \mathrm{~kg}$ and serum $\mathrm{Cr}<1.5 \mathrm{mg} / \mathrm{dL}$ who are receiving at least $2000 \mathrm{mg} /$ day of metformin and $2 \mathrm{mg} /$ day glimepiride with stable insulin dose and following routine diet and exercise regime for at least 12 weeks. At baseline, mean daily doses of the long acting or intermediate acting insulin's were 43IU for both groups and the mean daily doses of the premixed insulin preparations were 40 and 39IU for the Hydroxychloroquine and sitagliptin groups, respectively. Eligible patients continued their current insulin + metformin + sulfonyl urea regimen and entered a 2 -week run in period. Following this 2 -week period, eligible patients had baseline measurements and then were randomised (1:1) using a random manual allocation schedule to treatment with hydroxychloroquine $400 \mathrm{mg}$ OD or sitagliptin $100 \mathrm{mg}$ OD for 24 weeks.

During the study, patients not achieving progressively stricter glycaemic goals met criteria for rescue therapy that included an adjustment to their insulin dose, based on the clinical judgment of the investigator. Specifically, the glycaemic rescue criteria were FPG $>280 \mathrm{mg} / \mathrm{dl}$ after randomisation (day 1) through week 12 and FPG $>240 \mathrm{mg} / \mathrm{dl}$ after week 12 through week 24 . Patients showing increase in their baseline $\mathrm{HbA} 1 \mathrm{c}$ by $1 \%$ was considered as treatment failures and excluded from the study. These patients were treated appropriately by the investigator. These patients were included in the statistical analysis.

Patients with a history of any retinopathy of any grade including diabetic retinopathy, evidence of an imminent need for retinal laser therapy, uncorrected visual acuity $<20 / 100$, abnormal visual fields, difficulty to examine optic disc, or evidence of retinal pigment epithelial abnormalities and patients with history or risk of macular edema were excluded from the study.

Primary objective of the study is to evaluate and compare mean change in glycated hemoglobin (HbA1c) levels at week 24 from baseline between and within treatment groups. Secondary objective to compare the percentage of patients achieving HbAlc level of $<7.0 \%$ between treatment groups at the end of week 24 and to evaluate and compare mean change in the Fasting plasma glucose (FPG) and 2-hr postprandial plasma glucose (PPG), Body weight and Serum creatinine.

\section{RESULTS}

Of the 1260 insulin treated patients screened, a total of 681 were randomised to either once daily hydroxychloroquine $(\mathrm{n}=338)$ or sitagliptin $(\mathrm{n}=343)$ (Figure 1). Baseline characteristics and demographics of the randomised patients were similar between groups (Table 1). After randomisation, 600 patients completed the 24-week study, with similar proportions of patients discontinuing the study in each group (Figure 1).

At baseline, in hydroxychloroquine group all patients had a mean HbA1c of $8.6 \%, 66 \%$ of patients had an HbA1c $<9.0 \%$, and the mean FPG was $179.1 \pm 59.6 \mathrm{mg} / \mathrm{dl}$ and PPP was $292.1 \pm 66.4$. Overall, the mean duration of diabetes was 12.5 years, $64 \%$ of the subjects were on long acting or intermediate acting insulin therapy and $36 \%$ on premixed insulin preparations. 
Table 1: Baseline characteristics of the randomised population.

\begin{tabular}{|lll|}
\hline Characteristic & $\begin{array}{l}\text { Hydroxychloroquine 400mg + insulin } \\
+ \text { Met + Glime }(\mathbf{n}=\mathbf{3 0 0})\end{array}$ & $\begin{array}{l}\text { Sitagliptin 100mg + insulin + Met } \\
+ \text { Glime }(\mathbf{n}=\mathbf{3 0 0})\end{array}$ \\
\hline Age, years & $58.3 \pm 9.1$ & $57.2 \pm 9.3$ \\
\hline Sex, $\mathbf{n}(\%)$, male & $164(55 \%)$ & $158(53 \%)$ \\
\hline Body weight $(\mathrm{kg})$ & $67.8 \pm 4.2$ & $67.6 \pm 4.1$ \\
\hline Body mass index $\left(\mathrm{kg} / \mathrm{m}^{2}\right)$ & $26.6 \pm 3.6$ & $27.1 \pm 3.4$ \\
\hline Duration of diabetes $($ years $)$ & $12.5 \pm 4.2$ & $12.8 \pm 3.9$ \\
\hline Serum Cr $(\mathrm{mg} / \mathrm{dl})$ & $0.93 \pm 0.19$ & $0.93 \pm 0.17$ \\
\hline HbA1c\% & $8.6 \pm 0.5$ & $8.7 \pm 0.5$ \\
\hline HbA1c distribution at baseline, $\mathbf{n}(\%)$ & $57(19 \%)$ \\
\hline HbA1c $<8 \%$ & $56(19 \%)$ & $154(51 \%)$ \\
\hline HbA1c $\geq 8$ to $<9 \%$ & $142(47 \%)$ & $89(30 \%)$ \\
\hline HbA1c $\geq 9 \%$ & $102(34 \%)$ & $175.8 \pm 51.6$ \\
\hline FPG, mg/dl & $179.1 \pm 59.6$ & $290.9 \pm 68.0$ \\
\hline PPG, mg/dl & $292.1 \pm 66.4$ & \\
\hline Type of insulin, $\mathrm{n}(\%)$ & $300(100 \%)$ \\
\hline All patients & $300(100 \%)$ & $41 \pm 10.6$ \\
\hline Total daily dose $(\mathrm{IU} /$ day) & $41 \pm 10.2$ & $104(35 \%)$ \\
\hline Premixed & $107(36 \%)$ & $39.6 \pm 11.2$ \\
\hline Total daily dose, IU/day & $40.0 \pm 11.7$ & $196(65 \%)$ \\
\hline $\begin{array}{l}\text { Long-acting or } \\
\text { intermediate-acting }\end{array}$ & $193(64 \%)$ & $43.5 \pm 25.7$ \\
\hline Total daily dose, IU/day & $43.2 \pm 29.9$ & \\
\hline
\end{tabular}

Table 2: Change in glycemic and other parameters from baseline at week 24.

\begin{tabular}{|c|c|c|c|c|c|c|}
\hline \multirow[t]{2}{*}{ Characteristic } & \multicolumn{3}{|c|}{$\begin{array}{l}\text { Hydroxychloroquine } 400 \mathrm{mg} \\
+ \text { insulin + Met + Glime, }(\mathrm{n}=300)\end{array}$} & \multicolumn{3}{|c|}{$\begin{array}{l}\text { Sitagliptin 100mg } \\
+ \text { insulin + Met + Glime, }(\mathrm{n}=\mathbf{3 0 0})\end{array}$} \\
\hline & Baseline & 24 weeks & $P$ value & Baseline & 24 weeks & $P$ value \\
\hline Body weight (kg) & $67.8 \pm 4.2$ & $66.6 \pm 4.3$ & $<0.0001$ & $67.6 \pm 4.1$ & $67.5 \pm 3.4$ & NS \\
\hline \multicolumn{7}{|l|}{ Serum $\mathrm{Cr}(\mathrm{mg} / \mathrm{dl})$} \\
\hline $\mathrm{HbA} 1 \mathrm{c} \%$ & $8.6 \pm 0.5$ & $7.3 \pm 0.5$ & $<0.001$ & $8.7 \pm 0.5$ & $7.8 \pm 0.5$ & $<0.001$ \\
\hline FPG, $\mathrm{mg} / \mathrm{dl}$ & $159.1 \pm 21.6$ & $128.1 \pm 16.1$ & $<0.001$ & $159.8 \pm 24.6$ & $136.6 \pm 17.4$ & $<0.001$ \\
\hline PPG, mg/dl & $282.2 \pm 32.4$ & $230.1 \pm 22.2$ & $<0.001$ & $282.9 \pm 31.9$ & $241.9 \pm 21.7$ & $<0.001$ \\
\hline Total daily dose (IU/day) & $41 \pm 10.2$ & $31.87 \pm 16.49$ & $<0.0001$ & $41 \pm 10.6$ & $37.91 \pm 11.71$ & $<0.0001$ \\
\hline
\end{tabular}

At baseline, in sitagliptin group all patients had a mean $\mathrm{HbAlc}$ of $8.7 \%, 70 \%$ of patients had an $\mathrm{HbAlc}<9.0 \%$, and the mean FPG was $179.1 \pm 59.6 \mathrm{mg} / \mathrm{dl}$ and PPP was 292.1 \pm 66.4 . Overall, the mean duration of diabetes was 12.5 years, $65 \%$ of the subjects were on long acting or intermediate acting insulin therapy and $35 \%$ on premixed insulin preparations.

Patients randomised in this trial were on long acting, intermediate acting or premixed insulin therapy in combination with metformin and glimepiride. Overall, the at 24 weeks, the addition of Hydroxychloroquine significantly ( $\mathrm{p}<0.001)$ reduced $\mathrm{HbAl}$ c by $1.3 \%$ compared with Sitagliptin which was $0.9 \%$. A greater proportion of patients achieved an $\mathrm{HbAlc}$ level $<7 \%$ while randomised to Hydroxychloroquine as compared with Sitagliptin (31 vs. $18 \%$ respectively; $\mathrm{p}<0.001)$. The addition of
Hydroxychloroquine significantly $(\mathrm{p}<0.001)$ reduced fasting plasma glucose by $31.0 \mathrm{mg} / \mathrm{dl}$ and post prandial plasma glucose by $52.1 \mathrm{mg} / \mathrm{dl}$ relative to sitagliptin where fasting plasma glucose reduced by $23.2 \mathrm{mg} / \mathrm{dl}$ and post prandial plasma glucose reduced by $41 \mathrm{mg} / \mathrm{dl}$ (Table 2).

$\mathrm{HbA1c}$ treatment response was similar in patients treated with long acting or intermediate acting insulin therapies compared to those treated with premixed insulin therapy.

The total number of hypoglycaemic episodes was 145 in the hydroxychloroquine group and 93 in the sitagliptin group. The incidence of hypoglycaemia was also higher in patients on premixed insulin compared with long or intermediate acting insulin's in both hydroxychloroquine and sitagliptin treatment groups. Of the 145 total episodes of hypoglycaemia in the hydroxychloroquine group, 139 
had a concurrent finger stick glucose value, of which 133 were $\leq 70 \mathrm{mg} / \mathrm{dl}, 71$ were $\leq 60 \mathrm{mg} / \mathrm{dl}$ and 32 were $\leq 50 \mathrm{mg} / \mathrm{dl}$. Of the 93 total episodes of hypoglycaemia in the sitagliptin group, 87 had a concurrent finger stick glucose value, of which 86 were $\leq 70 \mathrm{mg} / \mathrm{dl}$, 46 were $\leq 60 \mathrm{mg} / \mathrm{dl}$ and 28 were $\leq 50 \mathrm{mg} / \mathrm{dl}$. As expected, the patients who experienced at least one hypoglycemia episode had both lower HbA1c and FPG values at baseline regardless of treatment.

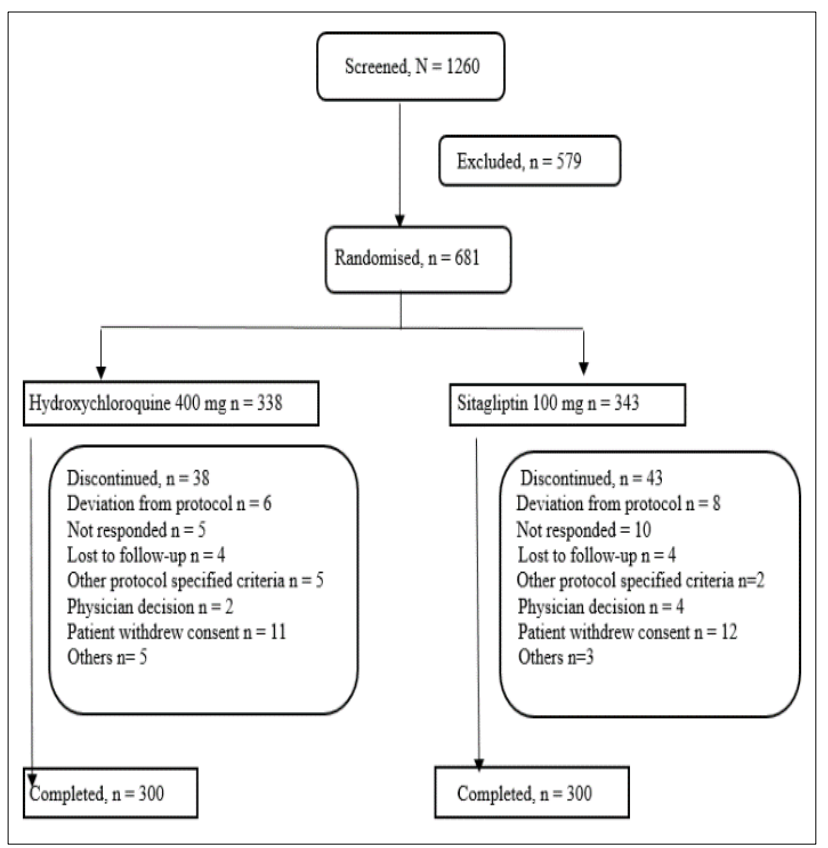

Figure 1: Patient disposition.

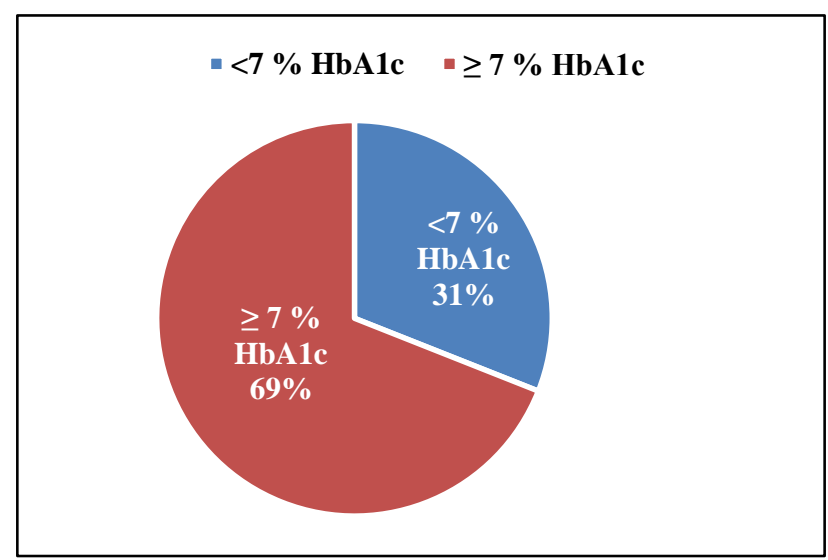

Figure 2: Proportion of patients achieved an HbA1c level $<7 \%$ with hydroxychloroquine.

A greater proportion of patients achieved an HbA1c level $<7 \%$ while randomised to hydroxychloroquine (Figure 2) as compared with sitagliptin (Figure 3) (31 vs. $18 \%$ respectively; $\mathrm{p}<0.001$ ).

At $24^{\text {th }}$ week eye scanning was done. Eye check-up done to evaluate corrective lenses, it has been found that in all patients $(n=600)$ pupils are equal and reactive to light and accommodation, Fundi-clear, no arteriolovenous nicking, no retinopathy.

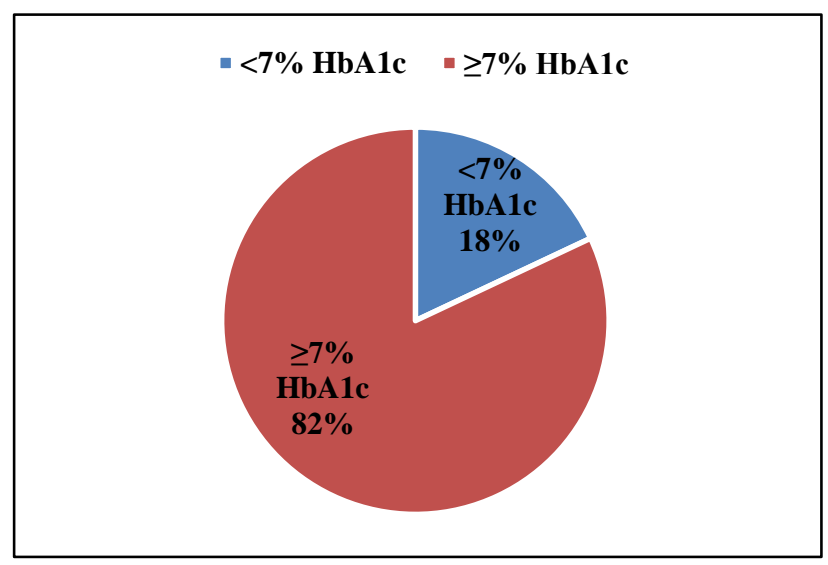

Figure 3: Proportion of patients achieved an $\mathrm{HbA1c}$ level $<7 \%$ with sitagliptin.

\section{DISCUSSION}

Tight glucose control is difficult to establish. If long-acting insulin or a twice daily injection of intermediate acting insulin is not adequate to control blood sugar levels, a more intensive insulin treatment regimen may be recommended. By increasing the dose of insulin, there is a risk of hypoglycemia, rapid heart rate, seizures and also weight gain.

This study assessed the efficacy and tolerability of hydroxychloroquine in patients with type 2 diabetes who were on a stable dose of insulin therapy with metformin and glimepiride. The addition of hydroxychloroquine to ongoing insulin therapy provided significant reductions in HbA1c, FPG and PPG compared with sitagliptin after 24 weeks, demonstrating that hydroxychloroquine improves fasting and postprandial glycaemic control in combination with insulin therapy. Hydroxychloroquine, when added to insulin therapy, enabled more patients to achieve theHbA1c target $<7$.

In the present study, a higher proportion of patients experienced symptomatic hypoglycaemia with the addition of hydroxychloroquine to ongoing insulin therapy. However, none of the hypoglycemia need severe medical assistance in both the groups. In contrast incidence of hypoglycemia was remarkably lower when compared to pioglitazone in patients uncontrolled on highest dose of metformin and sulfonylurea. Even in earlier studies, no severe hypoglycemia was reported when the hydroxychloroquine $400 \mathrm{mg}$ was compared with DPP4i as oral therapy. In a trial done by Baidya A et al, demonstrated that addition of hydroxychloroquine $400 \mathrm{mg}$ when added to ongoing insulin therapy has the potentiality to reduce the total daily insulin dose by $28 \%$.

It is quite obvious that few patients will not respond to the drug, even in this trial it has been seen that 5 patient in 
Hydroxychloroquine and 10 patients on sitagliptin has not responded initially who were excluded from the trial.

The deterioration of metabolic control leading to therapeutic failure is a common problem in patients with NIDDM, and is well known from previous studies. ${ }^{14,15}$ Hence, the most important finding in our study is the rapid deterioration of glycaemic control that we observed in our hydroxychloroquine treated patients as compare to sitagliptin. This suggests that with Hydroxychloroquine hyperglycaemia is not a stable condition, but progressively increases in nearly all these patients, demanding close monitoring and aggressive treatment if near normoglycaemia is the therapeutic goal. Long-term data from major studies like UK Prospective Diabetes Study has already established the importance of tight and early glucose control to prevent complications of diabetes. ${ }^{16}$ All the patients had known NIDDM for several years prior to inclusion and had at least partly preserved beta-cell function. The mean duration of diabetes at inclusion in this population was 12.6 years (Mean \pm SD), but it is known that many patients with NIDDM have had their disease for several years before diagnosis. ${ }^{17}$ It is therefore likely that a majority of patients in present study had the disease for 15 years or more at inclusion. In contrast to the finding in the UKPDS, our insulin-treated patients had a stable HbA1c throughout the study period in both the groups. This may be due to the small scale of present study with close followup of the patients and the use of intermediate-acting and regular insulin to best match the needs of the individual patient.

The study protocol did not allow changes to the doses of oral antidiabetic drugs (i.e. Metformin, glimepiride, Hydroxychloroquine and Sitagliptin) that were already being used, but the dose of insulin could be titrated. As a result, Hydroxychloroquine therapy resulted in a significant decrease of the insulin dose, which provided a new insight into the effects of concomitant therapy with a Hydroxychloroquine. In hydroxychloroquine group there was almost $22 \%$ reduction in total daily Insulin dose over 6 months period as compare to sitagliptin group where the reduction in total daily Insulin dose was only $7.5 \%$.

Most patients with type 2 diabetes are obese and an undesired side effect of certain antihyperglycaemic agents is increased body weight. ${ }^{18}$ Weight gain is typically observed with insulin therapy, reflective of improved glycaemic control. ${ }^{19}$ In the present study, highly significant ( $\mathrm{P}<0.0001)$ decrease in mean weight was observed from baseline i.e. $67.8 \pm 4.2$ to $66.6 \pm 4.3 \mathrm{Kg}$ at the end of trial with hydroxychloroquine, whereas body weight almost remains unchanged in sitagliptin group.

Several limitations of our trial are worth noting. First, the study design allowed adjustments of insulin dose (for ethical reasons), which could have made interpretation difficult. Second, the therapeutic approach represented by the current study may be considered uncommon. Third, there was no placebo comparator, forth study population was small. Because of the observational and retrospective design of the study, the possibility of selection bias cannot be ruled out. Information related to diet and lifestyle modification and information regarding dosing pattern of concomitant medication was not analysed. Data were collected only for a duration of 6 months, so there are limitations in commenting on durability of the treatment. Long-term studies to address the shortcomings of the present study are warranted.

\section{CONCLUSION}

Hydroxychloroquine decreases $\mathrm{HbA1c}$ in patients whose type 2 diabetes is poorly controlled with stable-dose insulin therapy with metformin and glimepiride. Combination therapy of Hydroxychloroquine and insulin was superior in $\mathrm{HbA} 1 \mathrm{c}$ reduction to DPP-4 inhibitors on insulin. On long term Hydroxychloroquine helps to reduce the dose of Insulin. This study showed that hydroxychloroquine 400 $\mathrm{mg}$ can be an effective alternative to DPP-4 inhibitor like sitagliptin for add on therapy to the patients who are poorly controlled with stable-dose insulin therapy with metformin and glimepiride.

Funding: No funding sources

Conflict of interest: None declared

Ethical approval: The study was approved by the Institutional Ethics Committee

\section{REFERENCES}

1. Gerstein HC, Pais P, Pogue J, Yusuf S: Relationship of glucose and insulin levels to the risk of myocardial infarction: a case controlled study. J Am Coll Cardiol. 199; 3:612-9.

2. Reaven GM: Pathophysiology of insulin resistance in human disease. Phys Rev. 1997;75:473-86.

3. Matthews DR, Cull CA, Stratton IM, Holman RR, Turner RC: UKPDS 26: Sulphonylurea failure in noninsulin-dependent diabetic patients over six years: UK Prospective Diabetes Study (UKPDS) Group. Diabet Med. 1998;15:297-303.

4. Turner RC, Cull CA, Frighi V, Holman RR. Glycemic control with diet, sulfonylurea, metformin, or insulin in patients with type 2 diabetes mellitus: progressive requirement for multiple therapies (UKPDS 49). UK Prospective Diabetes Study (UKPDS) Group. JAMA 1999;281:2005-12.

5. Hermansen K, Davies M, Derezinski T, Martinez RG, Clauson P, Home P. A 26-week, randomized, parallel, treat-to-target trial comparing insulin detemir with NPH insulin as add-on therapy to oral glucoselowering drugs in insulin-naive people with type 2 diabetes. Diabetes Care. 2006;29:1269-74.

6. Riddle MC, Rosenstock J, Gerich J. The treat-to-target trial: randomized addition of glargine or human NPH insulin to oral therapy of type 2 diabetic patients. Diab Care. 2003;26:3080-6.

7. Karasik A, Aschner P, Katzeff H, Davies MJ, Stein PP. Sitagliptin, a DPP-4 inhibitor for the treatment of 
patients with type 2 diabetes: a review of recent clinical trials. Curr Med Res Opin. 2008;24:489-96.

8. Pareek A, Chandurkar N, Thomas N. Efficacy and safety of hydroxychloroquine in the treatment of type 2 diabetes mellitus: a double blind, randomized comparison with pioglitazone. Curr Med Res Opin. 2014;30:1257-66.

9. Jagnani VK, Bhattacharya NR, Satpathy SC, Hasda GC, Chakraborty S. Effect of hydroxychloroquine on type 2 diabetes mellitus unresponsive to more than two oral antidiabetic agents. J Diabetes Metab. 2017;8:771.

10. Baidya A, Kumar Manish, Sailesh KP, Ahamed R. Study of comparative effect of hydroxychloroquine and vildagliptin on glycaemic efficacy and HbA1cin type 2 diabetes patients who were inadequately controlled with metformin and glimepiride dual therapy. JMSCR. 2018;6(4).

11. Prasad SS, Kumar SM, Kumar A, Alok, Ranjan R. Comparative Study to evaluate Effect of Hydroxychloroquine versus Sitagliptin as add on therapy in patients with Type 2 Diabetes inadequately controlled on combination with metformin and Gliclazide: a multicentre, Observational trial. Scholars Journal of Applied Medical Sciences. 2018;6(5).

12. Baidya A, Chakravarti HN, Saraogi RK, Gupta A, Ahmed R, et al. Efficacy of maximum and optimum doses of hydroxychloroquine added to patients with poorly controlled type 2 diabetes on stable insulin therapy along with glimepiride and metformin: association of high-sensitive c-reactive protein (hscrp) and glycosylated haemoglobin (hbalc). Endocrinol Metab Syndr. 2018;7:283-7.

13. Vilsbøll T, Rosenstock J, Yki-Järvinen H, Cefalu WT, Chen Y, Luo E, et al. Efficacy and safety of sitagliptin when added to insulin therapy in patients with type 2 diabetes. Diab Obes Metabol 2010 Feb;12(2):167-77.

14. Haupt E, Laube F, Loy H, Schöffling K. Secondary failures in modern therapy of diabetes mellitus with blood glucose lowering sulfonamides. Medical Clinic.1977; Sep;72(38):1529-36.

15. Groop L, Schalin C, Franssila-Kallunki A, Widén E, Ekstrand A, Eriksson J. Characteristics of non-insulindependent diabetic patients with secondary failure to oral antidiabetic therapy. Am J Med. 1989 Aug 1;87(2):183-90.

16. Harris MI, Klein R, Welborn TA, Knuiman MW. Onset of NIDDM occurs at least 4-7 yr before clinical diagnosis. Diabetes care. 1992 Jul 1;15(7):815-9.

17. Pi-Sunyer FX. The effects of pharmacologic agents for type 2 diabetes mellitus on body weight. Postgrad Med. 2008 Jan 1;120(2):5-17.

18. Inzucchi SE. Oral antihyperglycemic therapy for type 2 diabetes: scientific review. JAMA. 2002 Jan 16;287(3):360-72.

19. Holman RR, Paul SK, Bethel MA, Matthews DR, Neil HA. 10-year follow-up of intensive glucose control in type 2 diabetes. N Eng J Med. 2008 Oct 9;359(15):1577-89.

Cite this article as: Kumar V, Singh MP, Singh AP, Pandey MS, Kumar S, Kumar S. Efficacy and safety of hydroxychloroquine when added to stable insulin therapy in combination with metformin and glimepiride in patients with type 2 diabetes compare to sitagliptin. Int J Basic Clin Pharmacol 2018;7:1959-64. 